\title{
4,5-Dihydropyrrolo[1,2-a]quinoxalines: A Tunable and Regenerable Biomimetic Hydrogen Source
}

\author{
Zhang-Pei Chen, Mu-Wang Chen, Ran-Ning Guo, and Yong-Gui Zhou*
}

State Key Laboratory of Catalysis, Dalian Institute of Chemical Physics, Chinese Academy of Sciences, 457 Zhongshan Road, Dalian 116023, China.

\section{Supporting Information}

ABSTRACT: A series of tunable and regenerable biomimetic hydrogen sources, 4,5-dihydropyrrolo[1,2-a] quinoxalines, have been synthesized and applied in biomimetic asymmetric hydrogenation of 3 -aryl- $2 \mathrm{H}$-benzo[ $b][1,4]$ oxazines and 1 alkyl-3-aryl-quinoxalin-2(1H)-ones, providing the chiral amines with up to $92 \%$ and $89 \%$ ee, respectively.

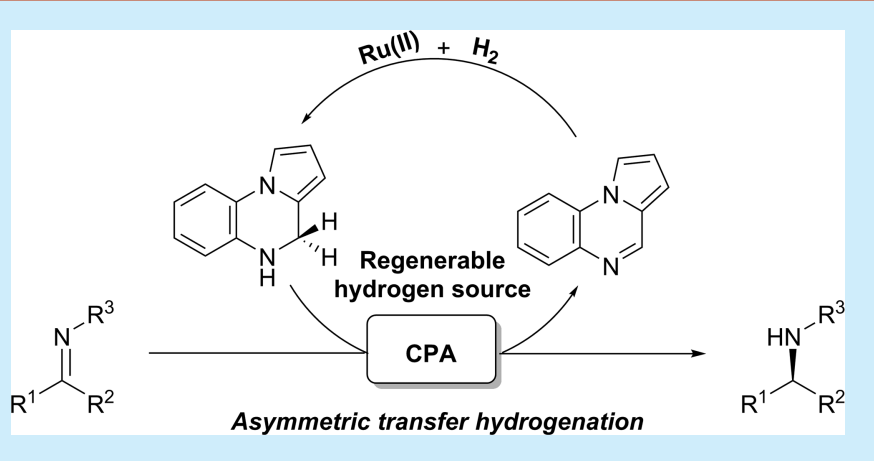

B iomimetic approaches of asymmetric-transfer hydrogenation (ATH) reactions have emerged as a preeminent synthetic method for the preparation of chiral molecules in the chemists' repertoire. ${ }^{1}$ Since pioneering reports in the 1980s, Hantzsch ester $(\mathrm{HEH})$ or related compounds ${ }^{2,3}$ were the only superior biomimetic hydride source for a long time, until Akiyama and co-workers demonstrated another hydride transfer reagent, benzothiazoline (Figure 1). ${ }^{4}$ However, in<smiles>[R]OC(=O)C1C=C([R])NC(C([R])=O)=C1[R]</smiles>

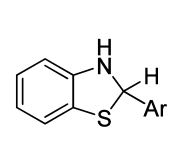

Benzothiazoline

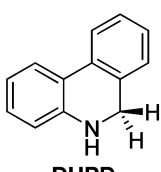

DHPD

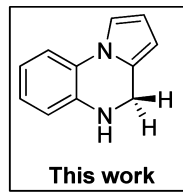

This work
Figure 1. Biomimetic hydrogen sources.

ordinary, stoichiometric or excessive amount of $\mathrm{HEH}$ or benzothiazoline was needed and a substantial number of dehydrogenation wastes generated in these transformations, which obviously limits the application of these specific hydrogen sources in both industry and academia. Consequently, the development of ATH reactions with regenerable hydrogen source is strongly desired.

Very recently, our group discovered that Hantzsch ester ${ }^{5}$ or dihydrophenanthridine (DHPD) ${ }^{6}$ could be regenerated in situ by $\mathrm{Ru}(\mathrm{II})$ complexes under hydrogen gas, which had been employed in the biomimetic asymmetric hydrogenation of heteroaromatics and cyclic imines with excellent enantioselectivities. Remarkably, the demand for hydrogen source could be reduced to a catalytic amount (10 mol \%). Although such progress has been achieved, the harsh regeneration conditions of $\mathrm{HEH}$ and limited derivatization possibility of DHPD impelled us to seek for easy tunable and regenerable versatile hydrogen sources.

The foregoing results have demonstrated that development of a regenerable biomimetic hydrogen source should fulfill the following requirements: (i) regenerate under mild conditions as well as with high hydride transfer ability and (ii) easy control of the reaction enantioselectivity and simultaneously with various derivatization possibilities. Based on these guidelines, we began our studies through investigating the transfer hydrogenation ability of 4,5-dihydropyrrolo[1,2-a]quinoxalines, which are easily obtained through the mild partial hydrogenation of corresponding pyrrolo[1,2-a]quinoxalines (Scheme 1). In addition, the latter compounds could be easily prepared and derived from the simple starting materials. ${ }^{7}$

Scheme 1. Ru-Catalyzed Generation of 2a from 1a with $\mathbf{H}_{2}$

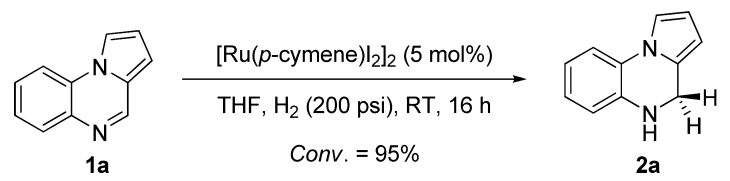

The readily available imine 3 -phenyl-2H-benzo[b][1,4]oxazine $3 \mathrm{a}^{8}$ was selected as the model substrate for condition optimization (Table 1). Gratifyingly, the exposure of ketimine $3 a$ with pyrrolo[1,2-a]quinoxaline 1a $(10 \mathrm{~mol} \%)$ in the presence of chiral phosphoric acid $5 \mathrm{a}$ and $\left[\mathrm{Ru}(p \text {-cymene }) \mathrm{I}_{2}\right]_{2}$ at room temperature furnished amine 4 a with $88 \%$ ee and $75 \%$ of conversion (entry 1). Notably, the reaction failed to proceed in the absence of la (entry 7 ). Through screening the reaction

Received: January 20, 2014

Published: February 26, 2014 
Table 1. Conditions Optimization for Biomimetic Asymmetric Hydrogenation of Imine $3 \mathrm{a}^{a}$
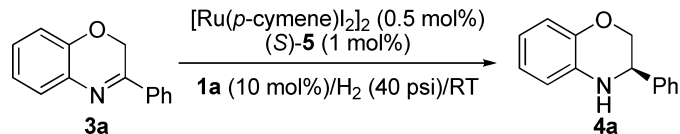

$3 a$

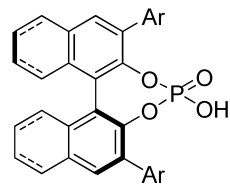

(S)-5a: $\mathrm{Ar}=\mathrm{Ph}$

(S)-5b: Ar = 9-Phenanthryl

(S)-5c: $A r=9$-anthryl

(S)-5d: $\mathrm{Ar}=\mathrm{Ph}[\mathrm{H} 8]$

$\mathrm{Ar}$

(S) $-5 \mathrm{e}: \mathrm{Ar}=\mathrm{H}$

\begin{tabular}{cclcc} 
entry & CPA & \multicolumn{1}{c}{ solvent } & conv $(\%)^{b}$ & ee $(\%)^{c}$ \\
1 & $(S)-5 \mathbf{a}$ & THF & 75 & 88 \\
2 & $(S)-5 \mathbf{a}$ & $\mathrm{CH}_{2} \mathrm{Cl}_{2}$ & 83 & 79 \\
3 & $(S)-5 \mathbf{a}$ & benzene & 28 & 90 \\
4 & $(S)-5 \mathbf{a}$ & THF/benzene $(1: 1)$ & 92 & 89 \\
5 & $(S)-5 \mathbf{a}$ & THF/benzene $(1: 2)$ & 95 & 91 \\
6 & $(S)-5 \mathbf{a}$ & THF/benzene $(2: 1)$ & 95 & 89 \\
$7^{d}$ & $(S)-5 \mathbf{a}$ & THF/benzene $(1: 2)$ & $<5$ & \\
$8^{e}$ & $(S)-5 \mathbf{a}$ & THF/benzene $(1: 2)$ & $>99$ & 92 \\
9 & $(S)-5 \mathbf{b}$ & THF/benzene $(1: 2)$ & 86 & 75 \\
10 & $(S)-\mathbf{5 c}$ & THF/benzene $(1: 2)$ & 90 & 77 \\
11 & $(S)-5 \mathbf{d}$ & THF/benzene $(1: 2)$ & 98 & 90
\end{tabular}

${ }^{a}$ Conditions: $0.15 \mathrm{mmol}$ of imine $3 \mathrm{a},\left[\mathrm{Ru}(p \text {-cymene }) \mathrm{I}_{2}\right]_{2}(0.5 \mathrm{~mol} \%)$, $(S)-5$ (1 mol \%), 1a (10 mol \%), $2 \mathrm{~mL}$ of solvent, $\mathrm{H}_{2}$ (40 psi), $38 \mathrm{~h}$, rt. ${ }^{b}$ Determined by ${ }^{1} \mathrm{H}$ NMR spectroscopy analysis of the crude product. ${ }^{c}$ Determined by HPLC. ${ }^{d}$ Without 1a. ${ }^{e} 40{ }^{\circ} \mathrm{C}$.

parameters including solvent, chiral phosphoric acid, and temperature, the most suitable conditions were established as (S)-5a/THF/benzene $(1: 2) / 40{ }^{\circ} \mathrm{C}$.

Then, a range of pyrrolo $[1,2-a]$ quinoxaline derivatives in the asymmetric-transfer hydrogenation reaction of imine 3a were evaluated with chiral phosphoric acid ( $S$ )-5a (Table 2). Interestingly, altering the group on the C8-position led to slightly fluctuating enantioselectivity, while the electronic effects of these substituent groups have a dramatic influence on the hydrogenation activity (entry 2 vs entry 3 ). This may because that electronic donor group promotes the hydride-

Table 2. Survey of Pyrrolo[1,2-a]quinoxalines for Biomimetic Asymmetric Transfer Hydrogenation of $3 \mathrm{a}^{a}$

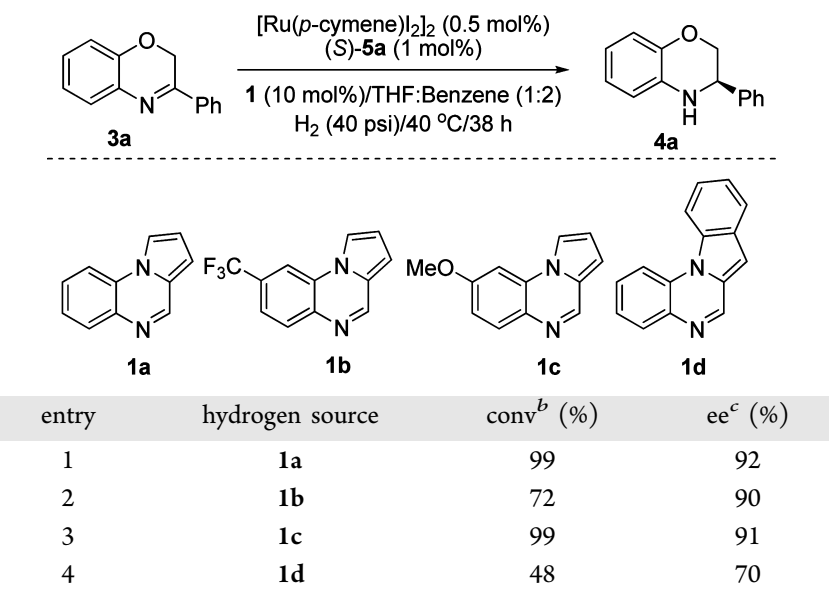

${ }^{a}$ Conditions: $0.15 \mathrm{mmol}$ of imine $3 \mathrm{a},\left[\mathrm{Ru}(p \text {-cymene }) \mathrm{I}_{2}\right]_{2}(0.5 \mathrm{~mol} \%)$, (S)-5a (1 mol \%), 1 (10 mol \%), THF/benzene $2 / 1(2 \mathrm{~mL}), \mathrm{H}_{2}(40$ psi), $38 \mathrm{~h}, 40{ }^{\circ} \mathrm{C} .{ }^{b}$ Determined by ${ }^{1} \mathrm{H}$ NMR spectroscopy analysis of the crude product. ${ }^{c}$ Determined by HPLC. transfer ability of the corresponding reduction-state substance. Such results are consistent with Zhu and Mayr's work on measuring and determining the thermodynamic parameters of various organic hydride donors by using titration calorimetry and electrochemical methods. ${ }^{9}$ As expected, when hydrogen source precursor $\mathbf{1 d}$ with weaker aromaticity was employed, the reactivity and enantioselectivity of asymmetric-transfer hydrogenation reaction dropped dramatically (entry 4). According to the survey above, the readily available pyrrolo[1,2-a]quinoxaline 1a was chosen as the best precursor of a regenerable hydrogen source.

With the optimized reaction conditions in hand, exploration of substrate scope was carried out (Table 3). All the 2-aryl-

Table 3. Biomimetic Asymmetric Transfer Hydrogenation of $3^{a}$

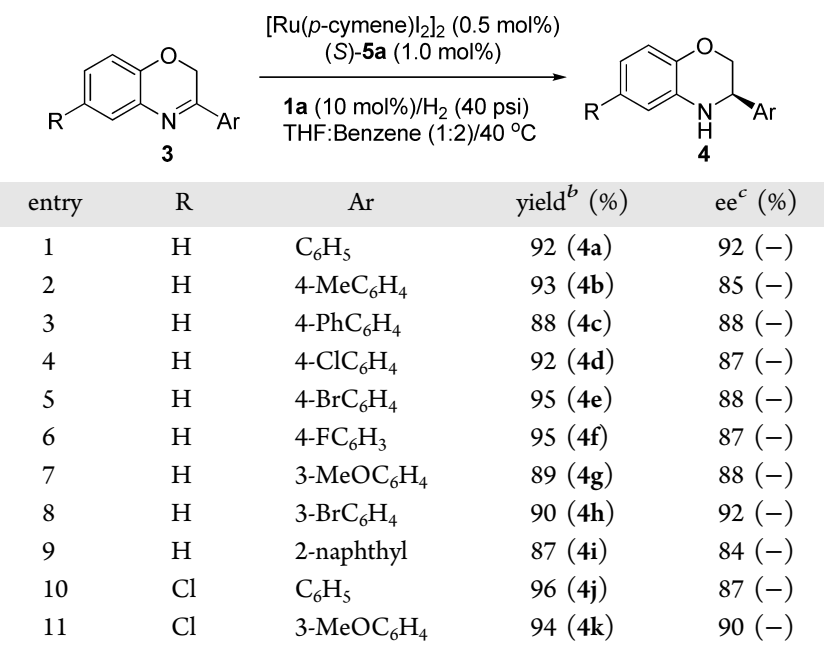

${ }^{a}$ Conditions: $0.2 \mathrm{mmol}$ of imine $3,\left[\mathrm{Ru}(p \text {-cymene }) \mathrm{I}_{2}\right]_{2}(0.5 \mathrm{~mol} \%)$, (S)-5a (1 mol \%), 1a (10 mol \%), THF/benzene $2 / 1$ ( $2 \mathrm{~mL}), \mathrm{H}_{2}(40$ psi), $38 \mathrm{~h}, 40{ }^{\circ} \mathrm{C} .{ }^{b}$ Isolated yield. ${ }^{c}$ Determined by HPLC.

substituted substrates were smoothly converted to the corresponding amines in high yields (87-96\%) with excellent enantioselectivities ( $84-92 \%$ ee). The electronic properties of the substituents had little effect on the catalytic activity and enantioselectivity (entry 7 vs entry 8 ). Notably, almost full conversion and satisfactory enantioselectivities were also provided when chloro was introduced at the C7-position (entries 10 and 11).

In order to further estimate the application possibility, we applied this attractive protocol to the hydrogenation of 1-alkyl3 -aryl-quinoxalin-2(1H)-ones (6). ${ }^{10}$ Gratifyingly, the reaction proceeded well with high enantioselectivities and reactivity (Scheme 2). In contrast to the reduction of $2 H$-benzo[b][1,4]oxazines 3 , in these instances the reactions were carried out in $\mathrm{CH}_{2} \mathrm{Cl}_{2}$ /benzene with $1 \mathrm{c}$ as the regenerable hydride source.

Since the research on thermodynamic driving forces of Hantzsch esters and related organic hydride donors to release hydride has become a very important field of chemistry, the hydride-transfer ability of diisopropyl 2,6-dimethyl-1,4-dihydropyridine-3,5-dicarboxylate (8), DHPD, and 1a were estimated by means of examining three parallel competing reactions of reducing $3 \mathbf{a}$ with phosphoric acid $5 \mathbf{e}$ in $\mathrm{CDCl}_{3}{ }^{11}$ Through ${ }^{1} \mathrm{H}$ NMR analysis, the hydride-transfer ability is established as Hanztsch ester $\mathbf{8}>$ DHPD > 1a (Scheme 3). Nevertheless, it is quite conceivable that 1a, located toward the bottom of the rank of hydride-donating abilities, could act as an 
Scheme 2. Biomimetic Asymmetric-Transfer Hydrogenation of Quinoxalin-2(1H)-ones $6^{a, b}$

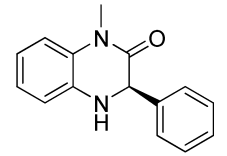

7a: $85 \%$ ee, $97 \%$ conv. MOM<smiles>CC(C)(C)CN1C(=O)[C@H](c2ccccc2)Nc2ccccc21</smiles>

7c: $86 \%$ ee, $95 \%$ conv.

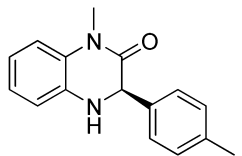

7b: $84 \%$ ee, $93 \%$ conv.

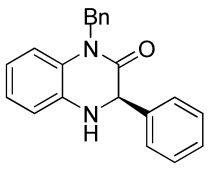

7d: $89 \%$ ee, $98 \%$ conv.
${ }^{a}$ Conditions: $0.2 \mathrm{mmol}$ of quinoxalin-2(1H)-ones 6, $[\mathrm{Ru}(p$-cymene)$\left.\mathrm{I}_{2}\right]_{2}(0.5 \mathrm{~mol} \%),(S)-5 \mathrm{a}$ (4 mol \%), $\mathbf{1 c}(10 \mathrm{~mol} \%), \mathrm{CH}_{2} \mathrm{Cl}_{2} /$ benzene $2 / 1(2 \mathrm{~mL}), \mathrm{H}_{2}$ (500 psi), $38 \mathrm{~h}, 40{ }^{\circ} \mathrm{C} .{ }^{b}$ Conversion was determined by ${ }^{1} \mathrm{H}$ NMR spectroscopy analysis of the crude product. Enantiomeric excess was determined by HPLC.

Scheme 3. Hydride-Transfer Ability Sequence ${ }^{a}$
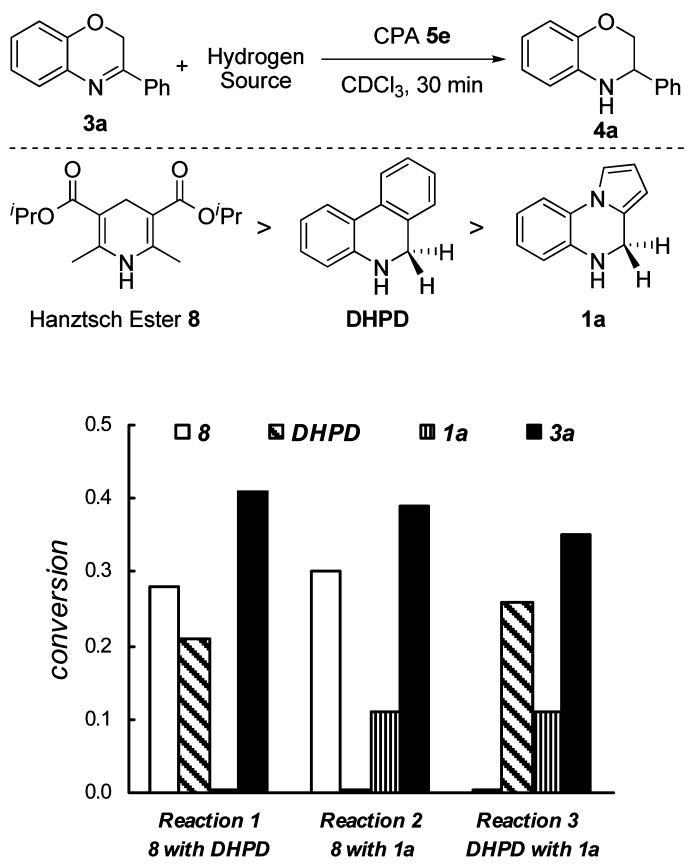

${ }^{a}$ Conditions: $0.1 \mathrm{mmol}$ of imine $3 \mathrm{a}$, hydrogen source (1 equiv, respectively), $( \pm)-5 \mathrm{e}(1 \mathrm{~mol} \%)$ were added to a nitrogen-protected NMR tube, then $\mathrm{CDCl}_{3}(1 \mathrm{~mL})$ was added, and the mixture was reacted for $30 \mathrm{~min}$ at ambient temperature. The conversion was determined by NMR analysis of this mixture.

important complement to the hydrogen source library as well as a potentially efficient reductant in accessing selective hydrogenation of molecules containing more than one unsaturated bond. It is necessary to point out that different hydride sources have diverse hydride transfer abilities and distinct selectivities under specified conditions, and this knowledge will shed light on the mechanism illustration and new organohydride sources for ATH reactions or other related reactions. ${ }^{12}$

In conclusion, a series of tunable and regenerable hydrogen sources, 4,5-dihydropyrrolo[1,2-a]quinoxalines, have been synthesized and employed as hydrogen sources in biomimetic asymmetric hydrogenation of 3-aryl-2H-benzo[b][1,4] oxa-zines and 1-alkyl-3-aryl-quinoxalin-2 $(1 \mathrm{H})$-ones, providing the chiral amines with up to $92 \%$ and $89 \%$ ee, respectively. The sequence of hydrogen-transfer ability of this new developed hydrogen source and other known hydrogen sources is established, which will provide useful information for development of new asymmetric-transfer hydrogenation reactions. Further detailed mechanistic studies of the reactions and investigations on the application of the regenerable chiral hydrogen sources are currently ongoing in our laboratory.

\section{ASSOCIATED CONTENT}

Supporting Information

Experimental details and full spectroscopic data for all new compounds. This material is available free of charge via the Internet at http://pubs.acs.org.

\section{AUTHOR INFORMATION}

\section{Corresponding Author}

*E-mail: ygzhou@dicp.ac.cn.

Notes

The authors declare no competing financial interest.

\section{ACKNOWLEDGMENTS}

We are grateful for financial support from the National Natural Science Foundation of China (21125208 and 21372220) and the National Basic Research Program of China (2010CB833300).

\section{REFERENCES}

(1) For the reviews, see: (a) Adolfsson, H. Angew. Chem., Int. Ed. 2005, 44, 3340. (b) Rosen, J. Chemtracts 2005, 18, 65. (c) Ouellet, S. G.; Walji, A. M.; MacMillan, D. W. C. Acc. Chem. Res. 2007, 40, 1327. (d) Connon, S. B. J. Org. Biomol. Chem. 2007, 5, 3407. (e) You, S.-L. Chem.-Asian J. 2007, 2, 820. (f) Wang, C.; Wu, X.; Xiao, J. Chem.Asian J. 2008, 3, 1750. (g) Rueping, M.; Sugiono, E.; Schoepke, F. R. Synlett 2010, 852. (h) Rueping, M.; Dufour, J.; Schoepke, F. R. Green Chem. 2011, 13, 1084. (i) Vries, J. G.; MrŠić, N. Catal. Sci. Technol. 2011, 1, 727. (j) Zheng, C.; You, S.-L. Chem. Soc. Rev. 2012, 41, 2498. (k) McSkimming, A.; Colbran, S. B. Chem. Soc. Rev. 2013, 42, 5439.

(2) (a) Zehani, S.; Gelbard, G. J. Chem. Soc., Chem. Commun. 1985, 1162. (b) Singh, S.; Batra, U. K. Indian J. Chem. 1989, 28B, 1. (c) Yang, J. W.; Fonseca, M. T. H.; List, B. Angew. Chem., Int. Ed. 2004, 43, 6660. (d) Ouellet, S. G.; Tuttle, J. B.; MacMillan, D. W. C. J. Am. Chem. Soc. 2005, 127, 32. (e) Yang, J. W.; Fonseca, M. T. H.; Vignola, N.; List, B. Angew. Chem., Int. Ed. 2005, 44, 108. (f) Yang, J. W.; Hechavarria Fonseca, M. T.; List, B. J. Am. Chem. Soc. 2005, 127, 15036. (g) Tuttle, J. B.; Ouellet, S. G.; MacMillan, D. W. C. J. Am. Chem. Soc. 2006, 128, 12662. (h) Mayer, S.; List, B. Angew. Chem., Int. Ed. 2006, 45, 4193. (i) Martin, N. J. A.; List, B. J. Am. Chem. Soc. 2006, 128, 13368. (j) Yang, J. W.; List, B. Org. Lett. 2006, 8, 5653. (k) Zhao, G.-L.; Córdova, A. Tetrahedron Lett. 2006, 47, 7417. (1) Zhou, J.; List, B. J. Am. Chem. Soc. 2007, 129, 7498. (m) Wang, D.-W.; Zeng, W.; Zhou, Y.-G. Tetrahedron: Asymmetry 2007, 18, 1103. (n) Rueping, M.; Theissmann, T.; Raja, S.; Bats, J. W. Adv. Synth. Catal. 2008, 350, 1001. (o) Rueping, M.; Antonchick, A. P. Angew. Chem., Int. Ed. 2008, 47, 5836. (p) Martin, N. J. A.; Cheng, X.; List, B. J. Am. Chem. Soc. 2008, 130, 13862. (q) Han, Z.-Y.; Xiao, H.; Chen, X.-H.; Gong, L.-Z. J. Am. Chem. Soc. 2009, 131, 9182 For reviews on asymmetric transfer hydrogenation reactions with Hantzsch esters, see ref 1.

(3) For recent works on asymmetric transfer hydrogenation reactions with Hantzsch esters, see: (a) Schneider, J. F.; Lauber, M. B.; Muhr, V.; Kratzer, D.; Paradies, J. Org. Biomol. Chem. 2011, 9, 4323. (b) Rueping, M.; Theissmann, T.; Stoeckel, M.; Antonchick, A. P. Org. Biomol. Chem. 2011, 9, 6844. (c) Chen, M.-W.; Chen, Q.-A.; Duan, Y.; Ye, Z.-S.; Zhou, Y.-G. Chem. Commun. 2012, 48, 1698. (d) Anderson, J. C.; Koovits, P. J. Chem. Sci. 2013, 4, 2897. (d) Patil, N. T.; Raut, V. S.; Tella, R. B. Chem. Commun. 2013, 49, 570. (e) Yin, Q.; Wang, S.- 
G.; You, S.-L. Org. Lett. 2013, 11, 2688. (f) Shi, F.; Tan, W.; Zhang, H.-H.; Li, M.; Ye, Q.; Ma, G.-H.; Tu, S.-J.; Li, G. Adv. Synth. Catal. 2013, 355, 3715. (g) Saito, K.; Kajiwara, Y.; Akiyama, T. Angew. Chem., Int. Ed. 2013, 52, 13284. (h) Terada, M.; Li, F.; Toda, Y. Angew. Chem., Int. Ed. 2014, 53, 235.

(4) (a) Zhu, C.; Akiyama, T. Org. Lett. 2009, 11, 4180. (b) Zhu, C.; Akiyama, T. Synlett 2011, 1251. (c) Saito, K.; Akiyama, T. Chem. Commun. 2012, 48, 4573. (d) Zhu, C.; Akiyama, T. Adv. Synth. Catal. 2010, 352, 1846. (e) Zhu, C.; Akiyama, T. Tetrahedron Lett. 2012, 53, 416. (f) Zhou, J.-Q.; Sheng, W.-J.; Jia, J.-H.; Ye, Q.; Gao, J.-R.; Jia, Y.X. Tetrahedron Lett. 2013, 54, 3082. (g) Sakamoto, T.; Horiguchi, K.; Saito, K.; Mori, K.; Akiyama, T. Asian J. Org. Chem. 2013, 2, 943. (h) Sakamoto, T.; Mori, K.; Akiyama, T. Org. Lett. 2012, 14, 3312. (i) Henseler, A.; Kato, M.; Mori, K.; Akiyama, T. Angew. Chem., Int. Ed. 2011, 50, 8180. (j) Shibata, Y.; Yamanaka, M. J. Org. Chem. 2013, 78, 3731.

(5) Chen, Q.-A.; Chen, M.-W.; Yu, C.-B.; Shi, L.; Wang, D.-S.; Yang, Y.; Zhou, Y.-G. J. Am. Chem. Soc. 2011, 133, 16432.

(6) (a) Chen, Q.-A.; Gao, K.; Duan, Y.; Ye, Z.-S.; Shi, L.; Yang, Y.; Zhou, Y.-G. J. Am. Chem. Soc. 2012, 134, 2442. (b) Lu, L.-Q.; Li, Y.; Junge, K.; Beller, M. Angew. Chem., Int. Ed. 2013, 52, 8382. (c) Du, W.; Yu, Z. Synlett 2012, 1300. (d) Shi, F.; Gong, L.-Z. Angew Chem., Int. Ed. 2012, 51, 11423.

(7) (a) Reeves, J. T.; Fandrick, D. R.; Tan, Z.; Song, J. J.; Lee, H.; Yee, N. K.; Senanayake, C. H. J. Org. Chem. 2010, 75, 992. (b) Pereira, M.; de, F.; Thiéry, V. Org. Lett. 2012, 14, 4754.

(8) For recent works on asymmetric reduction of benzoxazines, see ref 6a and: (a) Rueping, M.; Sugiono, E.; Steck, A.; Theissmann, T. Adv. Synth. Catal. 2010, 352, 281. (b) Rueping, M.; Antonchick, A. P.; Theissmann, T. Angew. Chem., Int. Ed. 2006, 45, 6751. (c) Jiang, Y.; Liu, L.-X.; Yuan, W.-C.; Zhang, X.-M. Synlett 2012, 1797. (d) Gao, K.; Yu, C.-B.; Wang, D.-S.; Zhou, Y.-G. Adv. Synth. Catal. 2012, 354, 483. (e) Hu, J.; Wang, D.-Y.; Zheng, Z.; Hu, X.-P. Chin. J. Chem. 2012, 30, 2664. (f) Zhang, Z.; Ji, Y. R; Wojtas, L.; Gao, W.-Y.; Ma, S.; Zaworotko, M. J.; Antilla, J. C. Chem. Commun. 2013, 49, 7693. (g) Liu, X.-W.; Wang, C.; Yan, Y.; Wang, Y.-Q.; Sun, J. J. Org. Chem. 2013, 78, 6276. (h) Fleischer, S.; Zhou, S.; Werkmeister, S.; Junge, K.; Beller, M. Chem.-Eur. J. 2013, 19, 4997. (i) Núñez-Rico, J. L.; VidalFerran, A. Org. Lett. 2013, 15, 2066.

(9) For selected works on measuring and determining the thermodynamic parameters of various organic hydride donors, see: (a) Richter, D.; Mayr, H. Angew. Chem., Int. Ed. 2009, 48, 1958. (b) Zhu, X.-Q.; Liu, Y.; Zhao, B.-J.; Cheng, J.-P. J. Org. Chem. 2001, 66, 370. (c) Zhu, X.-Q.; Li, H.-R.; Li, Q.; Ai, T.; Lu, J.-Y.; Yang, Y.; Cheng, J.-P. Chem.-Eur. J. 2003, 9, 871. (d) Zhu, X.-Q.; Cao, L.; Liu, Y.; Yang, Y.; Lu, J.-Y.; Wang, J.-S.; Cheng, J.-P. Chem.—Eur. J. 2003, 9, 3937. (e) Zhu, X.-Q.; Dai, Z.; Yu, A.; Wu, S.; Cheng, J.-P. J. Phys. Chem. B 2008, 112, 11694. (f) Zhu, X.-Q.; Liu, Q.-Y.; Chen, Q.; Mei, L.-R. J. Org. Chem. 2010, 75, 789. (g) Zhu, X.-Q.; Deng, F.-H.; Yang, J.-D.; Li, X.-T.; Chen, Q.; Lei, N.-P.; Meng, F.-K.; Zhao, X.-P.; Han, S.H.; Hao, E.-J.; Mu, Y.-Y. Org. Biomol. Chem. 2013, 11, 6071.

(10) For recent works on asymmetric reduction of quinoxalin-2-ones, see ref 8i and: (a) Xue, Z.-Y.; Jiang, Y.; Peng, X.-Z.; Yuan, W.-C.; Zhang, X.-M. Adv. Synth. Catal. 2010, 352, 2132. (b) Rueping, M.; Tato, F.; Schoepke, F. R. Chem.-Eur. J. 2010, 16, 2688.

(11) Reaction 1: hydrogenation of $3 a$ with 1 equiv of 8 and DHPD. Reaction 2: hydrogenation of $3 a$ with 8 and 1a. Reaction 3: hydrogenation of 3a with DHPD and 1a.

(12) Notably, very recently, Akiyama demonstrated a brilliant chiral phosphoric acid-catalyzed oxidative kinetic resolution of indolines based on transfer hydrogenation to imines with indolines as the hydride source. See: Saito, K.; Shibata, Y.; Yamanaka, M.; Akiyama, T. J. Am. Chem. Soc. 2013, 135, 11740. 